\title{
Sleep and nocturnal acid reflux in normal subjects and patients with reflux oesophagitis
}

Department of Internal Medicine, University of Virginia, Charlottesville, Virginia, USA

N Friedin

$M$ J Fisher

W Taylor

D Boyd

P Surratt

R W McCallum

R K Mittal

Correspondence to:

Dr R K Mittal, Department of Internal Medicine, Box 145, Unternal Medicine, Box 145 University of Virgin

Charlottesville, Virginia

22908, USA.

Accepted for publication

3 December 1990

\begin{abstract}
Nocturnal gastro-oesophageal reflux may be important in the pathogenesis of reflux oesophagitis. This study aimed to determine whether: (1) gastro-oesophageal reflux occurs during sleep in patients with reflux oesophagitis and, if so, to explore the mechanism, and (2) the sleep pattern of patients with oesophagitis is different from that of control subjects. After a standard evening meal, simultaneous manometric, oesophageal $\mathrm{pH}$, and polysomnographic recordings were obtained in 11 patients with endoscopic oesophagitis and 11 control subjects. Patients with gastrooesophageal reflux disease had significantly more total reflux episodes throughout the nocturnal monitoring period than control subjects $(105 v 6)$. Ninety two of 105 episodes of gastro-oesophageal reflux in patients occurred during the awake state and 10 during sleep stage II. A number of reflux episodes occurred during brief periods of arousal from the various sleep stages. Of the 105 reflux events recorded in patients, 42 were induced by transient lower oesophageal sphincter relaxation, 20 by stress reflux, 22 by free reflux mechanisms, and in 21 the mechanism was unclear. The sleep pattern and the time spent in each sleep stage was not different between the two groups. It is concluded that the awake state is crucial for the occurrence of nocturnal reflux episodes in normal subjects as well as in patients with reflux oesophagitis and that the difference between the frequency of gastro-oesophageal reflux between normal subjects and patients cannot be explained by different sleep patterns.
\end{abstract}

Nocturnal gastro-oesophageal reflux is considered to be important in the pathogenesis of reflux oesophagitis. ${ }^{12}$ In normal subjects it occurs by the mechanism of transient lower oesophageal sphincter relaxation. ${ }^{34}$ Reflux episodes and transient lower oesophageal sphincter relaxations in normal subjects have been reported to occur only in the awake periods. ${ }^{3}$ The mechanism of nocturnal gastro-oesophageal reflux in patients with reflux disease is not known. In patients with reflux oesophagitis, other mechanisms besides transient lower oesophageal sphincter relaxation, such as free reflux and stress reflux, may induce gastro-oesophageal reflux. ${ }^{56}$ The relation between reflux episodes induced by the latter mechanisms and sleep is unknown. In addition, the sleep pattern of patients with reflux disease in comparison with that in normal subjects is unknown. If gastrooesophageal reflux occurs only during the awake periods then a difference in sleep patterns may explain the increased frequency of nocturnal reflux episodes in patients.

This study aimed to determine whether: (1) gastro-oesophageal reflux occurs during sleep in patients with oesophagitis and, if so, to determine its mechanism during sleep and (2) the sleep pattern of patients with reflux disease is different from that of control subjects.

\section{Methods}

SUBJECTS

Eleven normal subjects, nine men and two women with a mean age of 39.6 (range 25-75) years, participated in this study. These subjects had no history of gastrointestinal symptoms specifically heartburn, dysphagia, regurgitation, nausea, or chest pain. Subjects were free of insomnia, pulmonary disease, and heart disease and none were taking any medicines known to interfere with smooth muscle function.

Eleven patients, eight men and three women with a mean age 38.7 (range 28-71) years, were recruited from the gastroenterology clinics at the University of Virginia. All subjects had undergone endoscopy and were known to have endoscopic evidence of oesophagitis - that is, erosions or linear ulcers, or both. In addition to oesophagitis, two patients had Barrett's mucosa. The patients were required to stop medications such as $\mathrm{H}_{2}$ receptor antagonist and smooth muscle active drugs for at least 24 hours and to refrain from cigarette smoking for at least 12 hours before the study. The protocol for this study was approved by the Human Investigations Committee of the University of Virginia and informed consent was obtained from each subject before the study.

\section{STUDY PROTOCOL}

All subjects fasted for at least six hours before the study. Subjects were admitted to a private room in the Clinical Research Center of the University of Virginia.

A motility catheter with a $6 \mathrm{~cm}$ Dent sleeve (Arndorfer Medical Specialties, Greendale, WN) with an attached micro $\mathrm{pH}$ electrode (Microelectrodes Inc, London Derry, NH) was passed transnasally. This assembly was positioned so that oesophageal $\mathrm{pH}$ was recorded at a location $5 \mathrm{~cm}$ proximal in the manometric lower oesophageal sphincter. Pressures were recorded simultaneously from the gastric fundus, lower oesophageal sphincter, oesophageal body (at sites 2 and $7 \mathrm{~cm}$ proximal to the lower oesophageal sphincter), and pharynx. The pharyngeal and oesophageal pressures were 
TABLE I Time spent and lower oesophageal sphincter pressure in each sleep stage per subject

\begin{tabular}{|c|c|c|c|c|c|c|}
\hline & \multicolumn{6}{|c|}{ Sleep stage } \\
\hline & Awake & $I$ & $I I$ & III & $I V$ & $R E M$ \\
\hline \multicolumn{7}{|l|}{ Control subjects } \\
\hline Total time $(\min )$ & $95 \cdot 0$ & $24 \cdot 0$ & $190 \cdot 0$ & $21 \cdot 0$ & $19 \cdot 0$ & $31 \cdot 0$ \\
\hline \multirow{2}{*}{\multicolumn{7}{|c|}{ Lower oesophageal }} \\
\hline & & & & & & \\
\hline$(\mathrm{mm} \mathrm{Hg})$ & $20 \cdot 1$ & $21 \cdot 5$ & $22 \cdot 4$ & $25 \cdot 0$ & $24 \cdot 7$ & $19 \cdot 7$ \\
\hline \multicolumn{7}{|l|}{ Patients } \\
\hline Total time (min) & $119 \cdot 0$ & $24 \cdot 0$ & $168 \cdot 0$ & $13 \cdot 0$ & $7 \cdot 0$ & $24 \cdot 0$ \\
\hline \multicolumn{7}{|l|}{ Lower oesophageal } \\
\hline $\begin{array}{l}\text { sphincter pressure } \\
\text { (mm Hg) }\end{array}$ & $20 \cdot 5$ & $24 \cdot 6$ & $22 \cdot 4$ & $26 \cdot 8$ & $32 \cdot 8$ & $23 \cdot 3$ \\
\hline
\end{tabular}

REM = rapid eye movement recordings were performed postprandially until 6 am the next morning. At approximately 9.30 $\mathrm{pm}$, sleep recording was started by monitoring the electroencephalogram, electro-oculogram and electromyogram on a Grass polygraph (Grass Instruments, Quincy, MA), which was synchronised with the Sensormedics polygraph. To assist with the identification of reflux episodes during the sleep periods, the $\mathrm{pH}$ and the lower oesophageal sphincter pressure were also recorded on the Grass polygraph. The entire apparatus was monitored continuously by means of a video camera from the sleep technician's polygraph room.

monitored by means of the water filled rather than the continuously perfused method in order to minimise the water loading of the subjects. The pharyngeal pressure was measured on the highest polygraph sensitivity so that a swallow signal could still be recorded even when the catheter was not continuously perfused. The lower oesophageal sphincter and gastric pressures were measured with a continuously perfused $(0.6$ $\mathrm{ml} / \mathrm{minute}$ ) Dent sleeve and side hole located $2 \mathrm{~cm}$ below the sleeve. The $\mathrm{pH}$ and manometric signals were recorded on an eight channel recorder (R-612 Sensormedics, Anaheim, CA). Once the tube position was satisfactorily established, 10 swallows of $5 \mathrm{cc}$ water each, spaced 30 seconds apart, were performed. Subjects were then given a $900 \mathrm{Kcal}$ meal, which comprised $40 \mathrm{~g}$ protein, $40 \mathrm{~g}$ carbohydrate, and $20 \mathrm{~g}$ fat. Liquids with a $\mathrm{pH}$ less than 4.0 were excluded from the diet. During the rest of the study subjects were permitted to have small sips of water only. The meal was given by $7 \mathrm{pm}$ in the evening. Continuous manometric and $\mathrm{pH}$
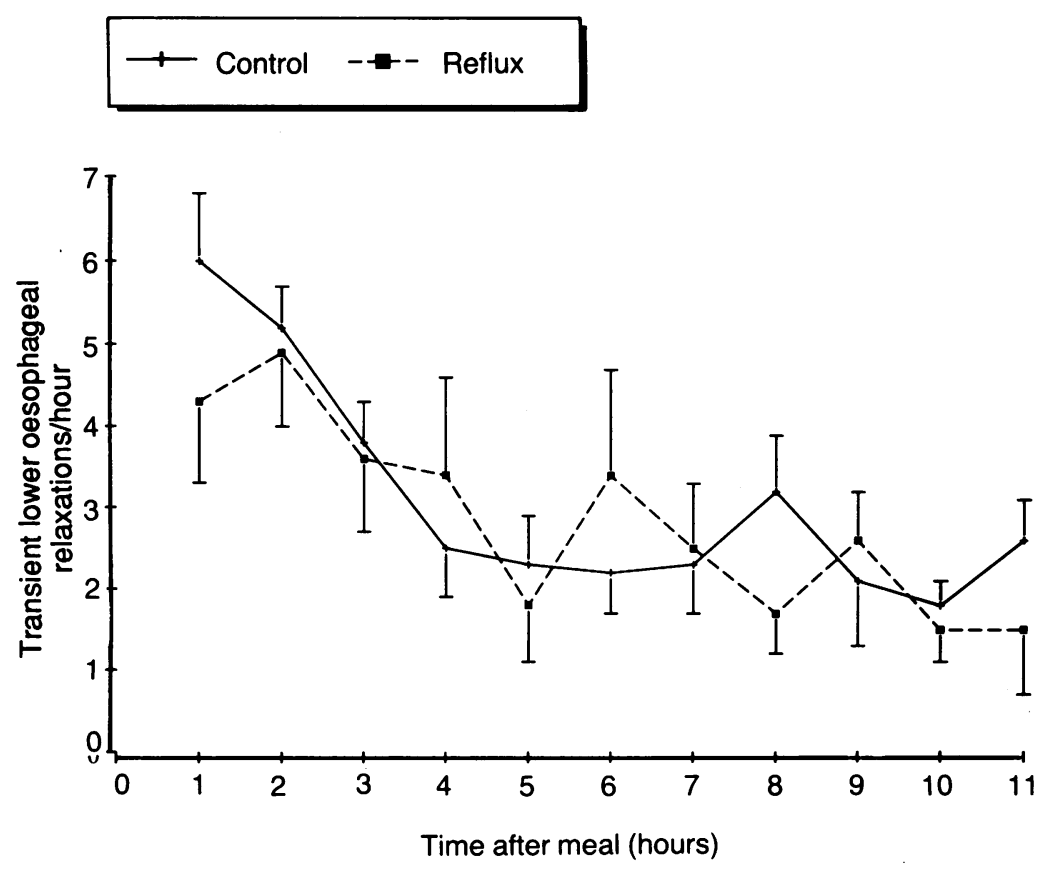

Figure 1: Transient lower oesophageal sphincter relaxation (TLOSR) frequency after a standard evening meal. The frequency at each hour represents the cumulative number of transient lower oesophageal relaxations in the previous hour. There are no significant differences between patients or controls at any time during the study. The frequency of TLOSRs was higher between patients or controls at any time during the study. The frequency of TLOSRs was higher
in the postprandial period in both patients and controls (hours 1 and 2 compared with hour 5).

\section{DATA ANALYSIS}

The sleep stage and manometric records were scored independently by WT and NF respectively. A reflux episode was defined as an abrupt fall of at least one $\mathrm{pH}$ unit from a baseline $\mathrm{pH}$ of 6.5 or less. The lower oesophageal sphincter pressure was measured as the highest pressure for each 30 seconds of the recording period in reference to the intragastric as the zero pressure. Transient lower oesophageal sphincter relaxation was defined as an abrupt fall in lower oesophageal sphincter pressure (unrelated to swallow) of at least $5 \mathrm{~mm} \mathrm{Hg}$ and lasting longer than five seconds. The transient lower oesophageal sphincter relaxations were further categorised into complete and incomplete. If the lower oesophageal sphincter pressure during relaxation was $<4 \mathrm{~mm} \mathrm{Hg}$ it was labelled as complete, otherwise it was considered to be incomplete. Sleep stages were determined according to the criteria proposed by Rechtschaffen and Kales.' Each minute of recording during sleep was scored for the sleep stage (I, II, III, or rapid eye movement (REM)), transient lower oesophageal sphincter relaxation, swallow, and reflux episode (present or absent). Percentages of each sleep stage and awake periods were calculated for each subject. The total time of sleep was defined as starting from the first sleep stage I and ending at $6 \mathrm{am}$. The number of reflux episodes in each sleep stage was determined for the two groups. The mechanisms of reflux during the various sleep stages were determined in the two groups. The mechanism of reflux was categorised into transient lower oesophageal sphincter relaxation, stress reflux, free reflux, and unclear. Reflux occurring at a time when there was a transient increase in intragastric pressure in the absence of transient lower oesophageal sphincter relaxation was labelled stress reflux. Free reflux was the term used when reflux occurred in the presence of a basal lower oesophageal sphincter pressure of $<4 \mathrm{~mm} \mathrm{Hg}$. If no pressure change in the stomach could be recognised, and lower oesophageal sphincter pressure was $>5 \mathrm{~mm} \mathrm{Hg}$ at the moment of gastro-oesophageal reflux, it was called an unclear mechanism. ${ }^{6}$ Data were entered on clinical information data management and analyses hardware and software (BBN Software, Cambridge, MA) and analysed using statistical analysis software (SAS Institute Inc, Cary NC). One and two way analysis of variance and paired and unpaired $t$ tests were used as appropriate to 


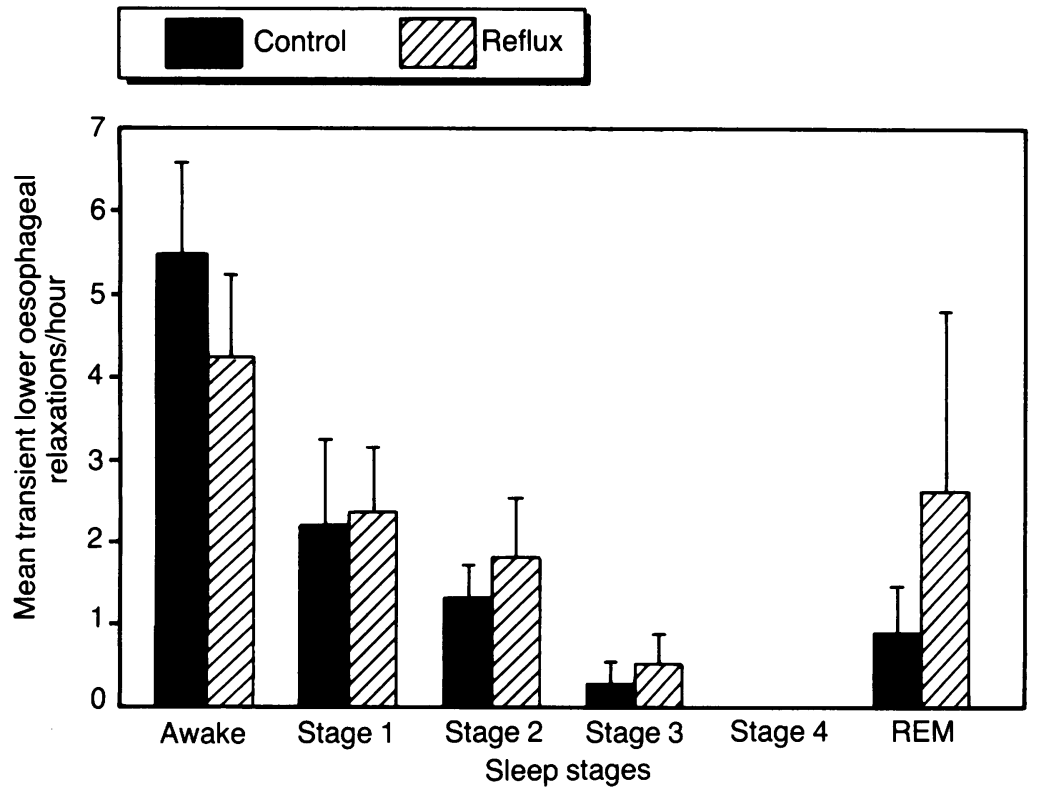

Figure 2: Effect of sleep stages on the frequency of transient lower oesophageal relaxations (TLOSR). There was a significant increase in the TLOSRs during awake periods compared with other sleep stages $(p<0.01)$. There were no differences between patients and controls in the $T L O S R$ frequency during any sleep stage.

assess statistical significance. Data are presented as mean (SEM).

\section{Results}

The mean (SEM) times spent by control subjects and patients in sleep were $6.32(0.31)$ and 5.90 $(0.49)$ hours respectively. These were not significantly different. Most of the time was spent in sleep stage II in both the groups. The total time spent in an awake state was higher in the patient group, but the difference was not statistically significant. Furthermore there was no difference in the time spent in the various sleep stages between the two groups (Table I) as
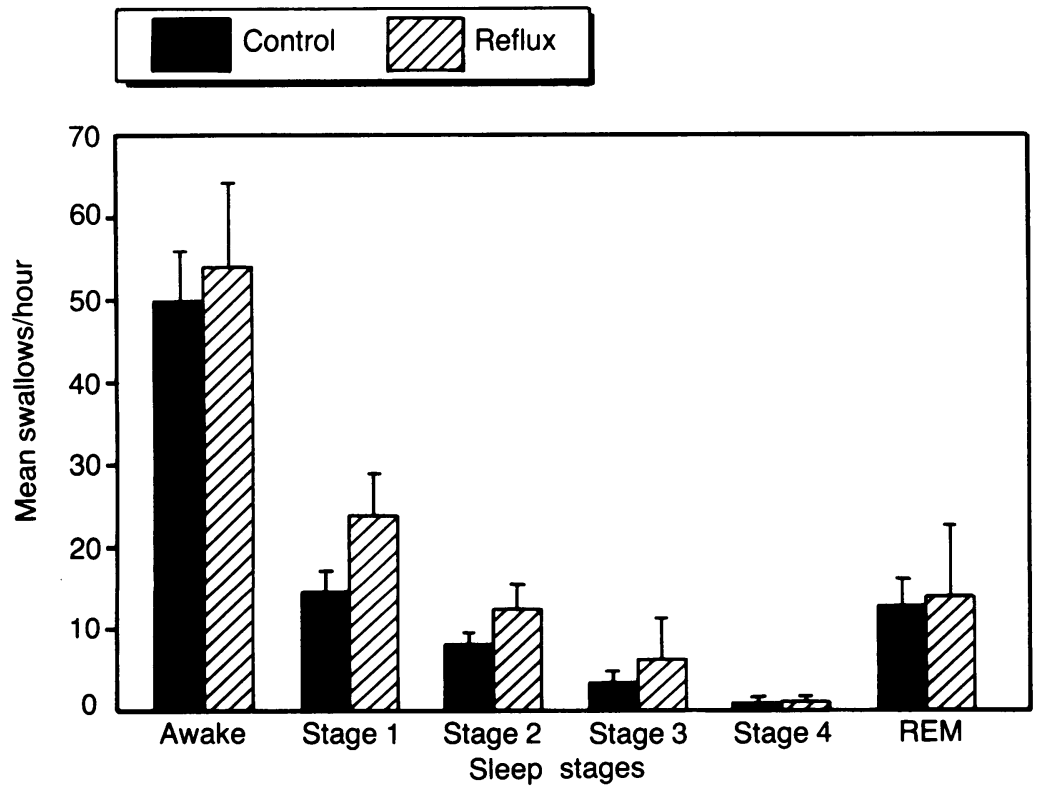

Figure 3: The effect of sleep stage on swallow frequency. Swallow frequency was assessed during concurrent polysomnographic monitoring. The greatest frequency of swallows per minute occurred during intermittent awake periods during the night. There was a significant increase in the swallow frequency in the awake state when compared with all of the other sleep stages $(p<0 \cdot 01)$. There were no differences in swallow frequency between control subjects and patients with reflux oesophagitis. assessed by weighted least square logistic regression of percentage sleep on groups and repeated for each subject. ${ }^{8}$ The number of awake periods interspersed between the various sleep stages was also not different in two groups - $11.6(1 \cdot 4)$ and 14.6 $(2 \cdot 3)$ in controls and patients respectively.

The resting lower oesophageal sphincter pressure in the two groups according to the sleep stage is shown in Table I. Within each group there was a trend towards higher pressure in sleep stages III and IV compared with the other sleep stages and the awake period, but the difference was not statistically significant. There was no difference in the lower oesophageal sphincter pressure between the two groups for the various sleep stages. (Based on $t$ tests.)

The transient lower oesophageal sphincter relaxation frequency in the period after the meal was highest in the first hour in the control subjects $(6(0 \cdot 7) /$ hour $)$ and in hour two in the reflux oesophagitis patients $(4.9(0.9) /$ hour) (Fig 1). The mean (SEM) percentage of complete transient lower oesophageal sphincter relaxations in the postprandial period was $73.0(8.4) \%$ in control subjects and $77 \cdot 2(7 \cdot 5) \%$ in patients with reflux oesophagitis $(p>0.05$ based on a two sample $t$ test).

Transient lower oesophageal sphincter relaxation frequency and the swallow frequency were analysed during each stage of sleep throughout the night (Figs 2 and 3). Two way analysis of variance was performed to test the group and sleep stage effect on transient lower oesophageal sphincter relaxations and swallows. In both cases, the group effect was not significant while the sleep stage effect was very significant $(p<0.0001)$. Duncan's multiple range tests found significantly more transient lower oesophageal sphincter relaxations and swallows in the awake state compared with other sleep stages for both control subjects and patients $(p<0.05)$. In the nocturnal monitoring period, there was no difference between the mean (SEM) number of complete transient lower oesophageal sphincter relaxations $(10.9(1 \cdot 7)$ in controls, $11 \cdot 2(3 \cdot 7)$ in patients, $p>0.05$ or the percentage of total transient lower oesophageal sphincter relaxations that were complete $(85.5(4.6) \%$ for controls, $70.7(8.3) \%$ for patients $p>0.05$ based on two sample $t$ tests.) Among the two groups there was a relation between the mean transient lower oesophageal sphincter relaxation frequency and the mean swallow frequency. The regression equation was found to be: mean transient lower oesophageal sphincter relaxation frequency $=$ $0.006+0.093 \times$ mean swallow frequency $(r=0.63$ $\mathrm{p}=0.0001)$ for controls and $=0.0011+$ $0.099 \times$ mean swallow frequency $(r=0.75$ $\mathrm{p}=0.0001$ ) for patients.

The reflux episodes occurred predominantly in the immediate postprandial period (Fig 4). Patients continued to have some reflux episodes during the night but the frequency of reflux diminished considerably in the control subjects. Three subjects in the patient group and nine in the control did not have any reflux episodes during the nocturnal period. The total number of reflux episodes recorded during nocturnal monitoring in the patients and controls were 105 
TABLE II Effect of sleep on frequency of reflux

\begin{tabular}{|c|c|c|c|c|c|c|c|}
\hline & \multicolumn{7}{|l|}{ Sleep stage } \\
\hline & $\begin{array}{l}\text { Total reflux } \\
\text { episodes }\end{array}$ & Awake & $I$ & $I I$ & III & $I V$ & $R E M$ \\
\hline $\begin{array}{l}\text { Control subjects } \\
\text { Patients }\end{array}$ & $\begin{array}{r}6 \\
105\end{array}$ & $\begin{array}{r}4 \\
92\end{array}$ & $\begin{array}{l}1 \\
0\end{array}$ & $\begin{array}{r}0 \\
10\end{array}$ & $\begin{array}{l}0 \\
0\end{array}$ & $\begin{array}{l}0 \\
1\end{array}$ & $\begin{array}{l}1 \\
2\end{array}$ \\
\hline
\end{tabular}

REM = rapid eye movement

TABLE III Mechanisms of nocturnal reflux in patients

\begin{tabular}{|c|c|c|c|c|c|c|c|}
\hline & \multicolumn{7}{|c|}{ Sleep stage } \\
\hline & Awake & $I$ & $I I$ & $I I I$ & $I V$ & $R E M$ & Total \\
\hline $\begin{array}{l}\text { TLOSR } \\
\text { Stress } \\
\text { Free } \\
\text { Unclear } \\
\text { Total }\end{array}$ & $\begin{array}{l}40 \\
17 \\
21 \\
14 \\
92\end{array}$ & $\begin{array}{l}0 \\
0 \\
0 \\
0 \\
0\end{array}$ & $\begin{array}{r}1 \\
2 \\
1 \\
6 \\
10\end{array}$ & $\begin{array}{l}0 \\
0 \\
0 \\
0 \\
0\end{array}$ & $\begin{array}{l}0 \\
1 \\
0 \\
0 \\
1\end{array}$ & $\begin{array}{l}1 \\
0 \\
0 \\
1 \\
2\end{array}$ & $\begin{array}{r}42 \\
20 \\
22 \\
21 \\
105\end{array}$ \\
\hline
\end{tabular}

$T L O S R=$ transient lower oesophageal relaxation. REM $=$ rapid eye movement.

and six respectively. One patient contributed 35 reflux episodes to the total number in the patient group but others contributed evenly. Two patients with Barrett's oesophagus had 18 gastrooesophageal reflux events during the nocturnal period. Most reflux events occurred in the awake stage (92 of 105 in the patient group) or during short arousal periods in sleep stage II (Table II). There were 10 episodes documented during sleep stage II. Close scrutiny of the tracings, however, showed a transient arousal of five to 10 seconds before the onset of a reflux event. Since sleep was recorded for each minute interval and most of that minute was spent in sleep stage II, the reflux was classified as occurring during sleep rather than during an awake period.

The mechanism of gastro-oesophageal reflux during the nocturnal monitoring period in patients is shown in Table III. Two patients refluxed exclusively by the mechanism of
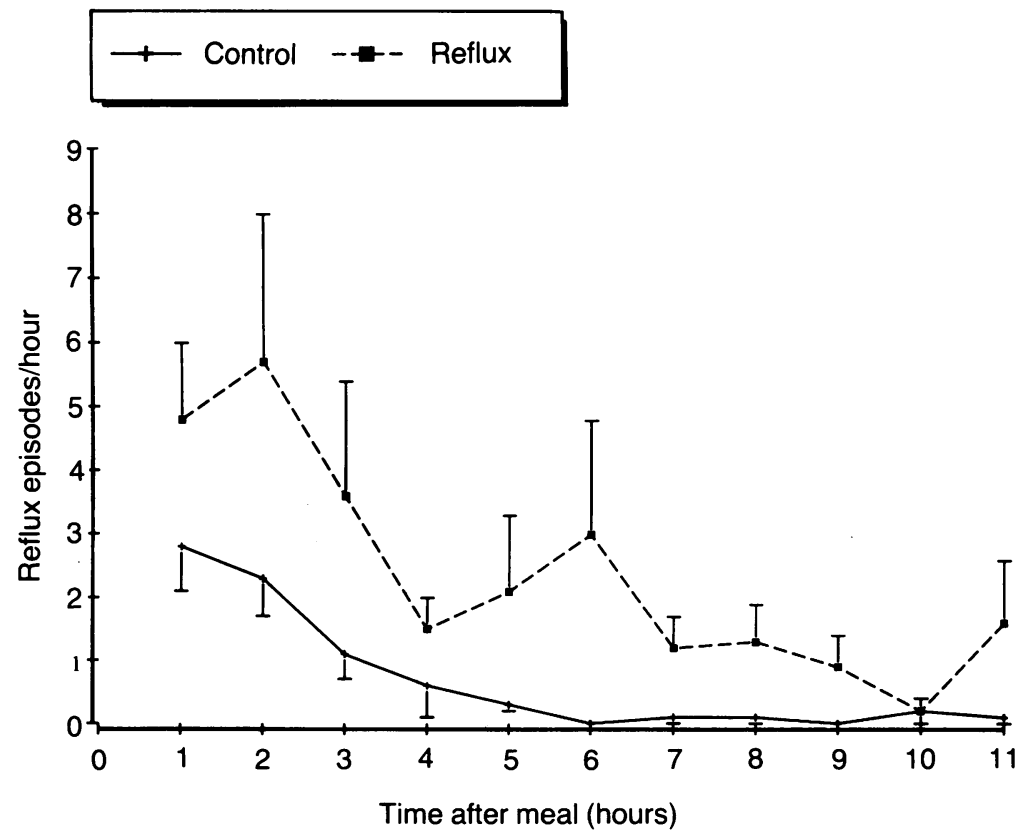

Figure 4: Frequency of reflux episodes after a standard evening meal. The frequency at each hour represents the cumulative number of reflux episodes occurring in the previous hour. There was a greater total cumulative frequency of reflux episodes after the standard meal in patients than in controls. The maximum frequency of reflux episodes occurred in the postprandial period in both patients and controls. transient lower oesophageal sphincter relaxation but in other reflux occurred by other mechanisms as well. Of 105 episodes of gastro-oesophageal reflux in the patient group, 42 were due to transient lower oesophageal sphincter relaxation, 20 due to stress induced reflux, 22 to free reflux, and in 21 the mechanism was unclear. Most reflux episodes caused by any mechanism occurred during the awake phase and transient arousals from sleep stage II (Table III). The control subjects experienced reflux by transient lower oesophageal sphincter relaxation only. Since the frequency of transient lower oesophageal sphincter relaxation between the two groups was similar, the higher number of reflux events in patients was due to two reasons (1): a higher number of transient lower oesophageal sphincter relaxations were associated with the gastro-oesophageal reflux and (2) gastrooesophageal reflux by mechanisms other than transient lower oesophageal sphincter relaxation did not occur in control subjects.

\section{Discussion}

In normal subjects, gastro-oesophageal reflux at night occurs only during periods of wakefulness because transient lower oesophageal sphincter relaxation, the major mechanism of reflux, occurs only during the awake state. ${ }^{3}$ Our study confirms these previously reported findings in normal subjects. In addition, our study shows that in patients with reflux disease, the vast majority of reflux events occur during the awake periods. Patients with reflux disease showed reflux by transient lower oesophageal sphincter relaxation only $40 \%$ of the time. The remaining $60 \%$ of reflux episodes were divided between free reflux, stress reflux, and unclear mechanisms. We find that even these mechanisms of reflux are operative only in the awake state. Even though a number of reflux episodes occurred during sleep stage II, close scrutiny of the tracings shows that they actually occurred during short arousal periods rather than sleep periods. They were misclassified in sleep stage II because of the limitation of the sleep stage scoring system. We used a standard scoring system that has been routinely used in the published reports. In this system sleep is scored in one minute intervals. The sleep stage present during most of the one minute interval is assigned to that minute even though there may be five to 10 second periods of arousal during that minute. Similar to the reflux events, the swallow events and transient lower oesophageal sphincter relaxations occurred only in the brief arousal periods during various sleep stages. We further analysed the data to determine if the reflux event caused secondary arousal in our subjects and found that reflux events always followed the arousal period, suggesting that reflux was not the primary cause of arousal.

Patients with reflux oesophagitis had more reflux events than the control subjects. Even though a large number of reflux events occurred during the immediate postprandial period, most patients continued to have reflux at night whereas control subjects did not. Similar findings have been reported by other investigators. ${ }^{2910}$ Since reflux occurred during awake periods only, we 
hypothesised that the reason for an increase in the frequency of night time reflux in patients with oesophagitis may be a poor sleep pattern. However, we found that this was not the case. There was no difference in the time spent in the various sleep stages by the two groups.

The published reports on sleep suggest that in order to monitor sleep adequately it should be recorded on two separate days. ${ }^{112}$ We studied our patients only once because we could not persuade them to participate for more than one day. Our subjects, for example, had a greater period of intermittent awakening than reported by other researchers. ${ }^{12}$ While it is possible that the sleep times in our subjects may not be comparable with the ones in other studies, we feel that our conclusions are valid since we compared our patients with control subjects, and both groups were studied in an identical fashion. It is possible, however, that if we had studied a larger number of patients and controls we might have detected small differences in their sleep patterns.

The effect of sleep on the frequency of swallowing had been reported before. ${ }^{13}$ Our study confirms previous reports. As with swallowing, the transient lower oesophageal sphincter relaxation frequency is also correlated to sleep stages, with the highest frequency in the awake state. It seems that there are a number of similarities in the swallow induced and transient lower oesophageal sphincter relaxation - both are mediated by the vagus nerve, ${ }^{14-16}$ wakefulness is essential to both of them, and both have been speculated to occur through the stimulation of the pharyngeal mechanoreceptors. ${ }^{17}{ }^{18} \mathrm{~A}$ number of these similarities suggest that common pathways are involved in the swallow induced lower oesophageal sphincter relaxation and transient lower oesophageal sphincter relaxation.

The precise reason for the increased frequency of nocturnal gastro-oesophageal reflux in our patients remains unclear. Stress, free, and unclear mechanisms of reflux are clearly present in the patient population only and account for some of this increased frequency. Is the transient lower oesophageal sphincter relaxation frequency different in the two groups, thereby accounting for the remaining reflux episodes? As in our previous study ${ }^{6}$ and the study of Baldi, ${ }^{19}$ we did not find any differences between patients and controls in the frequency of transient lower oesophageal sphincter relaxation, either in the immediate postprandial period or later on during the night. We also assessed whether the transient sphincter relaxations in patients were more complete because only complete relaxations are associated with the reflux episode. ${ }^{34}$ There was no difference in the absolute number or in the percentage of complete transient sphincter relaxations between patients and control subjects in either the postprandial or the nocturnal periods. It is true, however, that a larger number of transient lower oesophageal sphincter relaxations in patients were associated with reflux events. Why should this be the case? Even though it cannot be directly addressed from our study, it is possible that other factors such as delayed gastric emptying $^{20}$ (by providing a larger gastric reservoir) or presence of hiatal hernia ${ }^{21}$ in gastrooesophageal reflux patients (by holding a pool of acid close to the ooesophagus) may explain our observations.

1 Dodds WJ, Hogan WF, Helm JF, Dent J. Pathogenesis of reflux esophagitis. Gastroenterology 1981; 81: 376-94.

2 Johnson LF, DeMeester TR. Twenty-four hour pH monitoring of the distal esophagitis. Am $\mathcal{f}$ Gastroenterol $1974 ; 62: 325-32$.

3 Dent J, Dodds WJ, Friedman RH, et al. Mechanism of gastroesophageal reflux in recumbent human subjects. gastroesophageal reflux in

4 Mittal RK, McCallum RW. Characteristics of transient lower esophageal sphincter relaxation in humans. Am $\mathcal{F}$ Physio 1987; 252: G636-41

5 Dodds WJ, Dent J, Hogan WJ, et al. Mechanism of gastroesophageal reflux in patients with reflux esophagitis. $N E n g$ f Med 1982; 307: 1547-52.

6 Mittal RK, McCallum RW. Characteristics and frequency of transient relaxations of the lower esophageal sphincter in patients with reflux esophagitis. Gastroenterology 1988; 95 : 593-9.

7 Rechtschaffen A, Kales A, eds. A manual of standardized terminology, techniques and scoring system for sleep stages of terminology, techniques and scoring system for sleep stages of human subjects. Washington, DC:

8 Netter J, Wasserman W, Richard D. Applied linear statistical models. Homewood, IL: Irwin Inc, 1974: 326-35.

9 Fink SM, McCallum RW. The role of prolonged esophageal $\mathrm{pH}$ monitoring in the diagnosis of gastroesophageal reflux. FAMA 1984; 252: 1160-4.

10 DeMeester TR, Johnson LF, Joseph GJ, Toscan MS, Hall AW, Skinner DB. Patterns of gastroesophageal reflux in health and disease. Ann Surg 1976; 184: 459-69.

11 Agnew HW, Webb WB, William RL. The first night effect: an EEG study of sleep.Psychophysiology 1966: 2: 263-6.

12 Coble P, McPartland RJ, Silva WJ, Kupfer DJ. Is there a first night effect? (A Revisit). Biol Psychiatry 1974; 9: 215-9.

13 Orr WC, Johnson LF, Robinson MC. Effect of sleep on swallowing, esophageal peristalsis, and acid clearance. Gastroenterology 1984; 86: 814-9.

14 Ryan JP, Snape WJ, Cohen S. Influence of vagi cooling on esophageal function. Am $\mathcal{F}$ Physiol 1977; 232: 159-64.

15 Reynolds RPE Sharkawy TY, Diamant NE. Esophagea peristalsis in the cat: the role of central innervation assessed by transient vagal blockage. Can $\mathcal{F}$ Physiol Pharmocol 1985; 63: $122-30$.

16 Martin CJ, Patrikios J, Dent J. Abolition of gas reflux and transient lower esophageal sphincter relaxation by vagal blockade in the dog. Gastroenterology 1986; 91: 890-6.

17 Christensen J. Motor functions of the pharynx and oesophagus. In: Johnson JR ed. Physiology of the gastrointestinal tract. Vol In: Johnson JR ed. Physiology of the gastrointestinal trac

18 Paterson WG, Rattan S, Goyal RK. Experimental induction of isolated lower esophageal sphincter relaxation in anesthetized opossums. F Clin Invest 1986; 77: 1187-93.

19 Baldi F, Ferrarini F, Balestra R, Borioni D, Longanesi AM, Miglioli $M$, et al. Esophageal motor events at the occurrence of acid reflux and during endogenous acid exposure in healthy subjects and in patients with oesophagitis. Gut 1985; 26: $336-41$.

20 McCallum RW, Berkowitz DM, Levin E. Gastric emptying in patients with gastroesophageal reflux. Gastroenterology 1980 ; 80: $285-90$.

21 Mittal RK, Lange RC, McCallum RW. Identification and mechanism of delayed acid clearance in subjects with hiatus hernia. Gastroenterology 1987; 92: 130-5. 